\title{
Understanding the "SMART" features of hematopoietic stem cells and beyond
}

\author{
Shiru Yuan ${ }^{1}$, Guohuan Sun ${ }^{1}$, Yawen Zhang $^{1}$, Fang Dong ${ }^{1,2,3}$, Hui Cheng ${ }^{1,2,3^{*}}$ \& Tao Cheng ${ }^{1,2,3^{*}}$ \\ ${ }^{1}$ State Key Laboratory of Experimental Hematology, National Clinical Research Center for Blood Diseases, Institute of Hematology \& Blood \\ Diseases Hospital, Chinese Academy of Medical Sciences \& Peking Union Medical College, Tianjin 300020, China; \\ ${ }^{2}$ Center for Stem Cell Medicine, Chinese Academy of Medical Sciences, Tianjin 300020, China; \\ ${ }^{3}$ Department of Stem Cell \& Regenerative Medicine, Peking Union Medical College, Tianjin 300020, China
}

Received March 29, 2021; accepted May 10, 2021; published online July 30, 2021

\begin{abstract}
Since the huge success of bone marrow transplantation technology in clinical practice, hematopoietic stem cells (HSCs) have become the gold standard for defining the properties of adult stem cells (ASCs). Here, we describe the "self-renewal, multilineage differentiation, apoptosis, rest, and trafficking" or "SMART" model, which has been developed based on data derived from studies of HSCs as the most well-characterized stem cell type. Given the potential therapeutic applications of ASCs, we delineate the key characteristics of HSCs using this model and speculate on the physiological relevance of stem cells identified in other tissues. Great strides are being made in understanding the biology of ASCs, and efforts are now underway to develop safe and effective ASC-based therapies in this emerging area.
\end{abstract}

stem cell biology, adult stem cells, hematopoietic stem cells

Citation: Yuan, S., Sun, G., Zhang, Y., Dong, F., Cheng, H., and Cheng, T. (2021). Understanding the "SMART" features of hematopoietic stem cells and beyond. Sci China Life Sci 64, 2030-2044. https://doi.org/10.1007/s11427-021-1961-1

\section{Introduction}

It has taken several decades to understand how the regenerative capacity of the body can be harnessed to heal or treat tissues damaged as a result of disease or trauma (Mao and Mooney, 2015). Researchers are now focusing on adult stem cells (ASCs), which have the capacity for self-renewal, thereby generating the required cell types (Clevers, 2015). ASCs exist in various tissues, including the brain, cornea, dental pulp, and bone marrow, and reports on ASC-containing tissues are becoming increasingly common (Ali et al., 2016). Many patients with malignant and nonmalignant hematopoietic disorders and/or immune dysfunction have benefited from bone marrow transplants, thus highlighting

*Corresponding authors (Hui Cheng, email: chenghui@ihcams.ac.cn; Tao Cheng, email: chengtao@ihcams.ac.cn) hematopoietic stem cells (HSCs) as one of the most extensively characterized ASC types (Dulak et al., 2015). Advanced techniques have contributed to a greater understanding of the physiological features of ASCs at the single cell level and facilitated further optimization of cellular and molecular diagnostics (Xie et al., 2021). To better manipulate ASCs for therapeutic purposes, an in-depth understanding of their physiological biology is required. The key characteristics have been concisely captured using the new "self-renewal, multi-lineage differentiation, apoptosis, rest, and trafficking" or "SMART" model (Figure 1) (Cheng, 2008).

\section{S: Self-renewal}

In classical theory, ASCs have two distinct mechanisms of self-renewal: asymmetric division and symmetric division. 


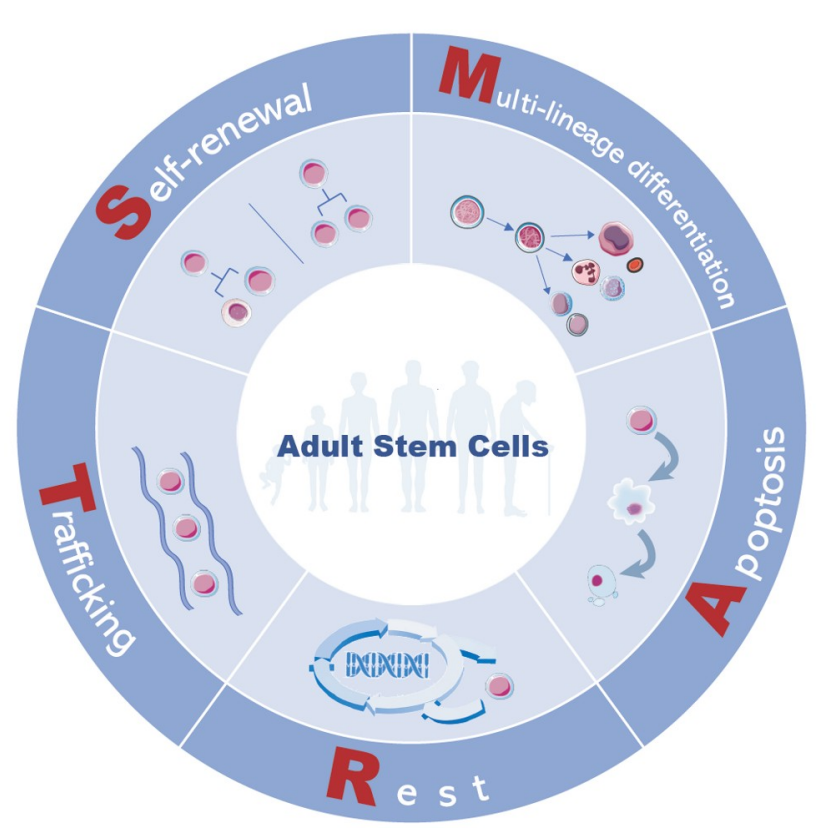

Figure 1 The hallmarks of ASCs illustrated using the "SMART" model of HSCs. This model constitutes the gold standard for defining the properties of ASCs.

Asymmetric division generates one daughter stem cell and one differentiated cell, whereas two daughter stem cells are produced by symmetric division (Morrison and Kimble, 2006). Asymmetric division is an effective strategy used to manage both self-renewal and differentiated cell production in a single division, thus maintaining tissue homeostasis and the stem cell pool simultaneously. Although ASCs tend to divide asymmetrically during steady-state conditions, they retain the ability to divide symmetrically to restore the stem cell pool after injury, as observed in hematopoietic systems (Cheng et al., 2019). The maintenance of HSC self-renewal capacity depends on the regulation of the cell itself (i.e., intrinsic regulation), and the regulation of various components in the hematopoietic microenvironment (i.e., extrinsic regulation) (Lucas, 2017). Here, we discuss the mechanisms underlying these two regulatory mechanisms in detail.

\section{Intrinsic regulatory mechanism}

The self-renewal capacity of ASCs, which is regulated by a complex network of transcription factors and signaling pathway molecules, correlates with the maintenance of their quiescent state.

\section{Classical signaling pathways and crosstalk}

The focus on Wnt signaling in ASCs originates from an observation linking canonical Wnt signaling with the maintenance of the ASC compartment in murine intestines (Korinek et al., 1998). Soluble Wnt3a protein induces the growth of highly purified human bone marrow HSCs in the absence of any other growth factors (Reya et al., 2003). Wnt pathway components and target genes have been identified as ASC markers in many other tissues. For example, leucinerich repeat-containing G-protein coupled receptor $5(\operatorname{Lgr} 5)$ is a Wnt target gene and Lgr5-positive $\left(\operatorname{Lgr} 5^{+}\right)$cells in the stomach, kidney, and ovary were identified as stem cells (Barker et al., 2007; de Lau et al., 2014). Furthermore, genetic knockout of Flamingo (Fmi) or Frizzled (Fz) 8 induces a decrease in the number of long-term HSC (LT-HSC), indicating that noncanonical Wnt signaling mediated by Fmi and Fz8 maintains quiescent LT-HSCs. These findings indicate the different roles of canonical and noncanonical Wnt signaling. While noncanonical Wnt signaling predominantly maintains quiescent LT-HSCs, the canonical Wnt signaling pathway is prominent in promoting the HSC activation and self-renewal (Sugimura et al., 2012). Notch receptors and ligands are widely expressed in the hematopoietic system (Wang et al., 2015). Hairy and enhancer of split-1 (Hes1), a classical target of the Notch signaling pathway, encodes a strong transcriptional repressor and is regulated by $\mathrm{Wnt} / \beta$ catenin signaling, which is an important indication of Wnt and Notch signaling crosstalk (Borggrefe et al., 2016).

The Smad signaling pathway is necessary for the transduction of signals downstream of the transforming growth factor- $\beta$ (TGF- $\beta$ ) family and bone morphogenetic proteins (BMPs). Low concentrations of TGF- $\beta$ stimulate the proliferation of myeloid-biased HSCs but inhibit the proliferation of lymphoid-biased HSCs (Blank and Karlsson, 2015; Challen et al., 2010). Moreover, Hedgehog (Hh) antibodies reduce the proliferation of uncommitted human hematopoietic cells. BMP inhibition using Noggin reduces Sonic hedgehog (Shh)-induced proliferation in a manner similar to that observed using anti-Hh, suggesting that Shh induces the expansion of primitive cells through mechanisms related to downstream BMP signals (Bhardwaj et al., 2001). Finally, the importance of fibroblast growth factor (FGF) signaling in facilitating HSC proliferation was confirmed through in vitro culture experiments. Bone marrow HSCs from FGF receptor 1 knockout mice showed impaired proliferative ability compared with HSCs of normal mice after 2 weeks of culture (Zhao et al., 2012).

\section{Transcription factors}

In addition to the classical signaling pathways mentioned above, several transcription factors are also involved in the intrinsic regulation of HSC self-renewal. Transcription factors of the forkhead box O (FoxO) family, particularly FoxO 3a, maintain the self-renewal capacity of HSCs by providing resistance to oxidative stress and initiating protective autophagy ( $\mathrm{Li}$ et al., 2015). Several studies have highlighted the vital importance of the Hox transcription factors in HSC self-renewal. Homeobox B4 (HoxB4) is considered to be a positive regulator of HSC self-renewal. HoxB4 over- 
expression significantly promotes the expansion of murine HSCs in vitro, and the amplified HSCs maintain the capacity for hematopoietic reconstruction in vivo. Hoxb5 $5^{+} \mathrm{HSCs}$ display long-term hematopoietic reconstruction capacity in primary and secondary recipient mice after transplantation, thus indicating that Hoxb5 serves as a marker of LT-HSCs. The distal element RARE (DERARE), located between the Hoxb4 and Hoxb5 genes, is a cis-regulatory element of Hoxb cluster genes and highly enriched in LT-HSCs. Deletion of DERARE inhibited Hoxb expression and reduced the frequency and absolute number of murine bone marrow HSCs via a methylation-dependent mechanism (Beslu et al., 2004; Chen et al., 2016; Qian et al., 2018).

\section{Non-coding RNAs}

Non-coding RNAs have a powerful role in regulating HSC expansion at a post-transcriptional level. Overexpression of microRNA-125 (miR-125) in human HSCs resulted in higher chimerism levels than in control-treated cells, confirming the role of miR-125 in regulating the self-renewal potential of HSCs (Wojtowicz et al., 2016). Competitive transplantation assays confirmed that miR-126 knockdown promoted HSC expansion without causing exhaustion (Lechman et al., 2012). Luo et al. identified 159 HSC-enriched lncRNAs (lncHSCs) by deep-sequencing of highly purified HSCs. Moreover, lncHSC-2 knockdown hampered the reconstitution of HSCs in secondary recipient mice, indicating that lncHSC-2 contributes to HSC self-renewal (Luo et al., 2015). The number of colony-forming units was significantly reduced after knocking down the expression of H19 lncRNA in $\mathrm{CD} 1^{+}$cells containing HSCs. Also, the decrease in H19 lncRNA resulted in a deficiency in fetal HSC formation and hypermethylation of certain hematopoietic transcription factor promoters (Zhou et al., 2019).

\section{Metabolic regulation}

Specific modes of metabolism are required to preserve the self-renewal capacity of HSCs. The asymmetric inheritance of lysosomes, autophagosomes, and mitophagosomes during autophagy and mitochondrial clearance regulates asymmetric HSC divisions (Loeffler et al., 2019). Mitochondrial quality is a vital factor in regulating HSC self-renewal. HSC expansion is accompanied by mitochondrial activation and metabolic conversion to oxidative phosphorylation. Mitochondria acquire cumulative damage during cell divisions, which activates mitochondrial autophagy, maintaining mitochondrial quality control. The intracellular hypoxic conditions are critical to the maintenance of HSCs. Increased frequencies of cycling HSCs and rising levels of intracellular reactive oxygen species (ROS) have been observed along with accumulated DNA damage under the influence of various stressors, which lead to compromised self-renewal capacity and ultimately, to HSC exhaustion (Ito and Ito, 2018).

\section{Extrinsic regulatory mechanism}

HSCs reside within a specialized hematopoietic microenvironment, termed the HSC niche, which is itself a functional unit of extrinsic regulation. The HSC niche is a complex structure composed of the extracellular matrix and different populations of niche cells, including osteoblasts, sinusoidal endothelial cells, perivascular cells, mesenchymal stem cells, and megakaryocytes and macrophages, which secrete cytokines and growth factors to enhance self-renewal of HSCs (Sugiyama et al., 2019).

\section{Cytokines and growth factors}

In addition to the cellular components, cytokines also play a key role in regulating HSC proliferation. In vitro studies indicated that high thrombopoietin (TPO) levels in combination with low stem cell factor (SCF) and fibronectin promoted the expansion of functional murine HSCs (Wilkinson et al., 2019). Bone marrow adipocytes promote HSC proliferation by secreting growth factors, including adiponectin and SCF (DiMascio et al., 2007; Zhou et al., 2017). Arteriolar endothelial and leptin receptor (Lepr)-expressing perivascular stromal cells are also important SCF sources. After deletion of SCF from endothelial and perivascular stromal cells, the frequency and absolute number of HSCs were reduced in murine bone marrow (Asada et al., 2017; Ding et al., 2012). A competitive transplantation assay showed that endothelial cells also secreted pleiotrophin (PTN) to regulate HSC self-renewal and maintain the HSC pool. Irradiated mice transplanted with $\mathrm{HSCs}$ from $\mathrm{PTN}^{-/-}$mice showed decreased hematopoietic reconstruction compared with mice transplanted with $\mathrm{HSCs}$ from $\mathrm{PTN}^{+/+}$mice (Figure 2) (Himburg et al., 2012).

\section{Biochemical characteristics}

ROS regulate HSC self-renewal and hematopoietic reconstruction by directly affecting the recipient microenvironment (Hu et al., 2019). The long-term hematopoietic reconstruction ability of murine bone marrow HSCs or human cord blood HSCs is significantly enhanced in vivo when the cells are collected under hypoxic conditions (3\% oxygen) rather than under normoxic conditions ( $21 \%$ oxygen). This phenomenon is mainly due to the increased mitochondrial permeability caused by the non-physiological level of oxidative stress under normoxic conditions, resulting in a sharp increase in intracellular ROS content (Mantel et al., 2015). Endosteal blood vessels mediate bone marrow HSC maintenance by providing a microenvironment with a low ROS level, while the intracellular ROS levels of HSCs are increased by the more permeable sinusoids through exposure to blood plasma leading to damage of their long-term selfrenewal capacity (Itkin et al., 2016). In general, microenvironmental regulation is an important mode of the 


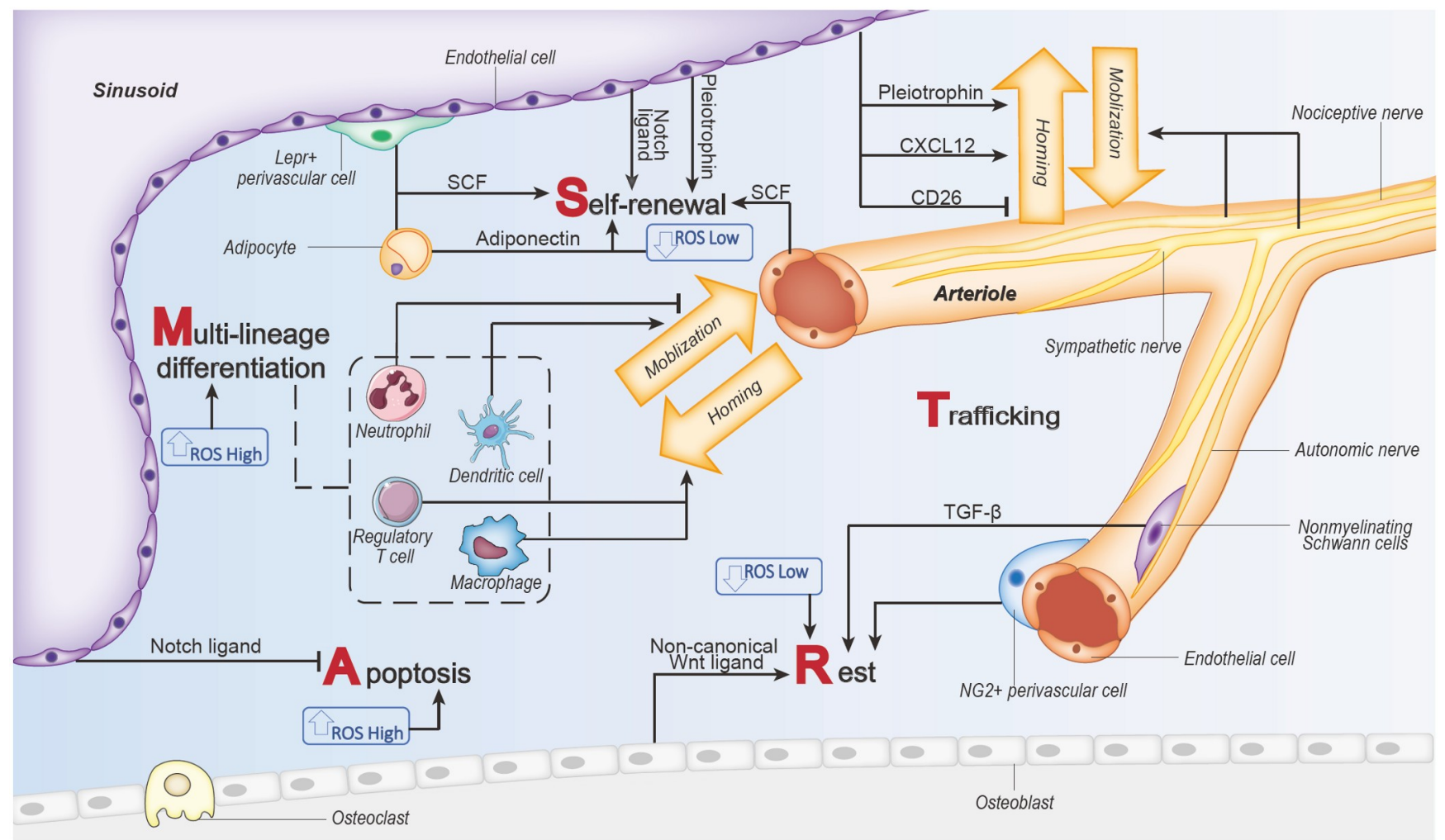

Figure 2 Schematic representation of the adult bone marrow showing the various cell types and factors that directly or indirectly regulate HSC activity.

extrinsic regulation required to maintain the self-renewal function of ASCs in the physiological state through mediators such as cytokines and ROS (Cheng et al., 2018).

HSC self-renewal is regulated by the elaborate interplay of both intrinsic and extrinsic regulators. In the fetal liver, HSC proliferation was weakened in the absence of activating transcription factor 4 (ATF4) due to the downregulated expression of cytokines, such as angiopoietin-like protein 3 in $\mathrm{ATF}^{-/-}$stromal cells (Zhao et al., 2015). Pleiotrophin increased the expression of HES1, a mediator of Notch signaling. Antagonism of Notch signaling blocked pleiotrophinmediated expansion of HSCs, suggesting that pleiotrophin promoted HSC expansion via Notch signaling (Himburg et al., 2010). SCF maintained HSCs by reducing intracellular ROS and regulated HSC self-renewal by transcription factors such as Slug and signal transducer and activator of transcription 5 (STAT5) (Itkin et al., 2012; Ludin et al., 2014; Zhang et al., 2017).

One of the main reasons for the lack of a major breakthrough in our ability to expand HSC in vitro is the difficulty in simulating the complexity of the hematopoietic microenvironment (Wilkinson et al., 2019). Although the barriers to stable expansion of HSCs in vitro remain, emerging achievements in scientific research cannot be ignored. For example, a new culture system using polyvinyl alcohol as a replacement for serum albumin reduces biological contaminants and supports huge expansion of functional murine
HSCs in vitro over a 1-month culture period. Successful engraftment was achieved using a limited number of HSCs derived from this albumin-free culture system without the requirement for radiation (Wilkinson et al., 2019). With regard to the expansion of human HSCs, small molecules such as StemRegenin 1 (SR1) and UM171 have been used in combination with cytokines to induce remarkable expansion of cord blood stem cells in vitro. Moreover, a recent singlearm, phase 1-2 study has suggested that HSC transplantation using single UM171-expanded cord blood is safe and feasible (Boitano et al., 2010; Cohen et al., 2020; Fares et al., 2014). Another study showed that substantial expansion and maintenance of long-term repopulating ability were achieved when human HSCs derived from cord blood and bone marrow were expanded in a three-dimensional (3D) degradable zwitterionic hydrogel culture system. The zwitterionic characteristics of the hydrogel and the 3D format simulated the HSC microenvironment and promoted HSC self-renewal, probably by inhibiting ROS production (Bai et al., 2019). We consider that, in the coming decade, more optimized culture systems for human HSCs will emerge and make significant contributions to regenerative medicine.

\section{M: Multi-lineage differentiation}

Currently, the HSC model is the best-characterized paradigm 
of ASC differentiation. Here, we discuss hematopoietic differentiation under steady-state or stress conditions.

\section{Differentiation during homeostasis}

HSCs reside at the top of a hierarchy of the production of all blood lineage cells. LT-HSCs are at the top of the hierarchical model, and the downstream short-term HSCs (ST-HSCs) differentiate into multi-potent progenitors (MPPs), which have no long-term self-renewal ability. MPPs mainly differentiate into common lymphoid progenitors (CLPs) with lymphoid potential and common myeloid progenitors (CMPs) with myeloid, erythroid, and megakaryocytic potential. CLPs differentiate into T, B, natural killer (NK) cells, and dendritic cells (DCs), while CMPs form bipotent granulocyte-macrophage (GMPs) and megakaryocyte-erythrocyte progenitors (MEPs), both of which mature into various functional cell lines. Although this huge pyramidlike differentiation model is widely used, it should be noted that the lineage output was assessed predominantly in colony or transplantation assays rather than in unperturbed hematopoiesis (Cheng et al., 2020; Laurenti and Göttgens, 2018).

Novel experimental murine models have been established to investigate unperturbed hematopoietic differentiation in the steady state. Using an inducible transposon tagging approach, the Camargo team discovered that progenitor cells, rather than HSCs, make a major contribution to steady-state hematopoiesis, and most MPPs differentiate into the myeloid lineage (Sun et al., 2014). However, the Reizis team reported a major contribution of HSCs to steady-state hematopoiesis based on genetic labeling studies (Sawai et al., 2016). These paradoxical observations may result from differences in labeling specificity and efficiency. Consequently, new techniques are required to resolve this controversy. Subsequently, the Reizis team employed a combination of lineage tracing, flow cytometry, and single-cell RNA sequencing (scRNAseq) to show that the megakaryocytic lineage emerged before other lineages. HSCs became committed to the megakaryocytic lineage within 1 week and then differentiated progressively to form erythroid, myeloid, and lymphoid progenitors, illustrating the sequential multi-lineage differentiation of HSCs in the steady state (Upadhaya et al., 2018). The classical pyramid-like differentiation model is supported by the Polylox recombination system devised by the Rodewald team, in which the spreading of barcodes indicated the multi-lineage or oligolineage fates of most HSC clones (Pei et al., 2017). An approach known as PolyloxExpress was subsequently developed for simultaneous analysis of fate and transcriptome profiles with HSC clones from the same fate category projected onto the same area of the transcriptional landscape (Pei et al., 2020). With the advances in technology and the information provided, it is likely that more stem and progenitor cell subtypes will be discovered, and the hierarchical model will be further revised (Cheng et al., 2020).

\section{Differentiation following non-homeostatic perturbation}

Emerging technologies based on scRNA-seq offer a greater insight into the variation in differentiation patterns under physiological or stress conditions. A new approach known as "FIT" has been proposed to elucidate HSC behavior following transplantation by combining function-based (F), immunophenotype-based (I), and transcriptome-based (T) methodologies (Dong et al., 2020a). In contrast to homeostasis, transplanted HSCs are likely to encounter diseased or damaged recipient microenvironments and undergo stress induced by the urgent requirement for hematopoietic reconstruction. Studies using scRNA-seq have shown that within $1 \mathrm{~d}$ after transplantation, the percentage of transcriptional HSCs (tHSCs) begin to decrease gradually since transplanted HSCs are immediately committed to differentiating into transcriptional MPPs (tMPPs) and even transcriptional megakaryocyte-erythrocytes (tMEs) and transcriptional granulocyte-monocyte-macrophages (tGMs). The appearance of tMEs and tGMs may result from the altered gene expression in tMPPs as a prelude to differentiation into the myeloid and erythroid lineages. Moreover, transplanted HSCs probably differentiate directly into erythroid and myeloid lineages even before the first cell division (Figure 3) (Dong et al., 2020b). After transplantation into unconditioned mice, HSC lineage commitment occurs with an equivalent contribution from each clone during differentiation. In contrast, in irradiated mice, a small subset of transplanted HSC clones expanded faster than others, and only a few HSC clones were involved in differentiation. Furthermore, HSC clones expanding dominantly in the CLPto-B-cell step were more inclined to exhibit lymphoid bias, whereas clones expanding dominantly in the HSC-to-MPP step were more likely to exhibit myeloid bias or no bias in irradiated mice. An increased number of helper cells or a reduced radiation dose resulted in more balanced HSC clones (Lu et al., 2019).

\section{A: Apoptosis}

The overgrowth of ASCs can be prevented by apoptosis, which is the most widely recognized mechanism of cell death in the physiological state. Apoptosis acts as an effective cellular quality control mechanism by removing dysfunctional and dangerous cells. The anti-apoptotic ability of ASCs required to maintain the stem cell pool at an adequate size is stronger than the anti-apoptotic ability of other mature cells occupying most of the body (Bergmann and Steller, 2010). Below, we discuss the moderate capacity of ASCs for 


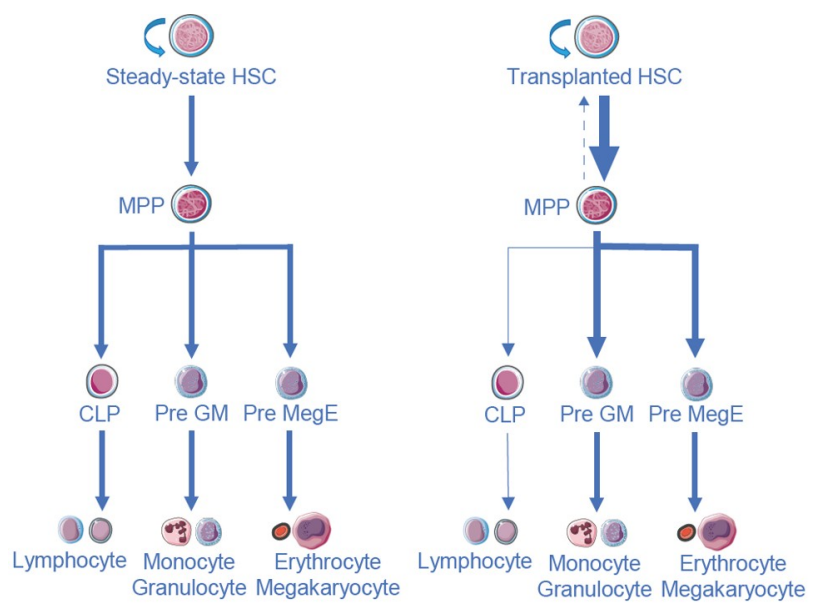

Figure 3 Schematic representation of hematopoietic differentiation under steady-state or stress condition. Unlike the classical hematopoietic hierarchical model (left panel), myeloid and erythroid differentiation is promoted after transplantation, while lymphoid differentiation is inhibited (right panel).

spontaneous apoptosis, in addition to their ability to resist apoptosis.

\section{Spontaneous apoptosis}

p53 is a mediator of the intrinsic apoptosis pathway and is regulated by consecutive ubiquitin-proteasome-induced degradation in the steady state (Bieging et al., 2014). p53deficient mice showed an increased number of HSCs, indicating that $\mathrm{p} 53$ activity negatively regulates the HSC pool size (Wang et al., 2011; Yamashita et al., 2016). p53 induces apoptosis of HSCs, protecting them from an accumulation of DNA damage (Figure 4) (Milyavsky et al., 2010). PUMA, a p53 target gene, encodes a pro-apoptotic protein with a powerful effect on $\mathrm{p} 53$-mediated apoptosis following radiation damage. The vast majority of $\mathrm{Puma}^{-/}$HSCs remained alive after lethal radiation, and in vitro experiments suggested more efficient DNA repair in radiation-exposed HSCs (Yu et al., 2010). In addition, stem cells in the gastrointestinal tract undergo p53-dependent apoptosis in response to genotoxic stimulation. The susceptibility to the induction of apoptosis via p53-dependent pathways is part of the homeostatic regulation of ASC numbers and a genome protective mechanism (Potten, 2001).

\section{Anti-apoptotic ability}

The tendency of ASCs to resist apoptosis, preventing exhaustion of ASCs in the steady state, should not be overlooked (Mohrin et al., 2010). Telomeres, a unique chromatin structure at the ends of chromosomes, tend to lose TG-rich repeats during cell division, leading to incomplete replication by conventional DNA polymerases (Flores et al., 2006).
Gradual shortening of the telomeres may eventually trigger chromosome instability and stimulate apoptosis. Certain ASC compartments express high levels of telomerase, a type of reverse transcriptase that adds telomeric repeats to the chromosome ends (Blasco, 2005). Telomerase is encoded by the telomerase reverse transcriptase (Tert) gene and the telomerase RNA component (Terc) gene (Collins and Mitchell, 2002). Mutations in the core components of Tert and Terc result in HSC exhaustion, which was observed in patients suffering from aplastic anemia characterized by bone marrow failure (Maciejewski and Risitano, 2003). Data show that murine telomere length in donor bone marrow cells is significantly decreased after just two rounds of HSC transplantation. Thus, it can be speculated that the role of telomerase in HSCs is to surmount telomere shortening during HSC division and prevent premature apoptosis (Allsopp et al., 2001). Both telomere length and telomerase levels have substantial impacts on ASC behavior, although further exploration is required to elucidate their precise roles in ASC apoptosis, such as the connection between various signaling pathways and the telomere state (Flores et al., 2006).

FMS-like tyrosine kinase 3 (Flt3) is uniformly expressed in human HSCs in both the bone marrow and the cord blood. An intact Flt3 signaling pathway is required to prevent HSCs from spontaneous apoptosis. Flt3 can upregulate myeloid cell leukemia-1 protein, which is a pro-survival member of the B-cell lymphoma-2 (BCL-2) protein family and an indispensable survival factor for hematopoiesis (Kikushige et al., 2008). The BCL-2 family is composed of intrinsic apoptosis pathway regulatory proteins with either proapoptotic or pro-survival functions that induce apoptosis or inhibit apoptosis, respectively (Edlich, 2018). BCL-2 upregulation is mediated by telomerase, which is abundantly expressed in HSCs and leads to their increased survival (Nitta et al., 2011). These findings suggest that HSCs have multiple interactive pro-survival mechanisms to cope with apoptosis stimulation and avoid unnecessary cell death (Yamashita et al., 2016).

There are still many problems to be resolved in this area. The currently available techniques for detecting apoptosis include labeling with activated caspase 3 antibody. More sensitive techniques for detecting apoptosis are in demand (Garcia-Lavandeira et al., 2015). Although studies showed that the BCL-2 overexpression increased HSC numbers in a transgenic model, it is still unclear whether or not BCL-2 acts by directly suppressing apoptosis since BCL-2 also alters HSC cycling (Domen et al., 2000). DNA-damaged HSCs exhibit stronger $\mathrm{p} 53$ activation than downstream progenitors, although the activation mechanism is still unclear (Yamashita et al., 2015). Above all, apoptosis should not be considered merely as a process of cell death since it plays a pivotal role in ASC homeostasis (Codispoti et al., 2019). 


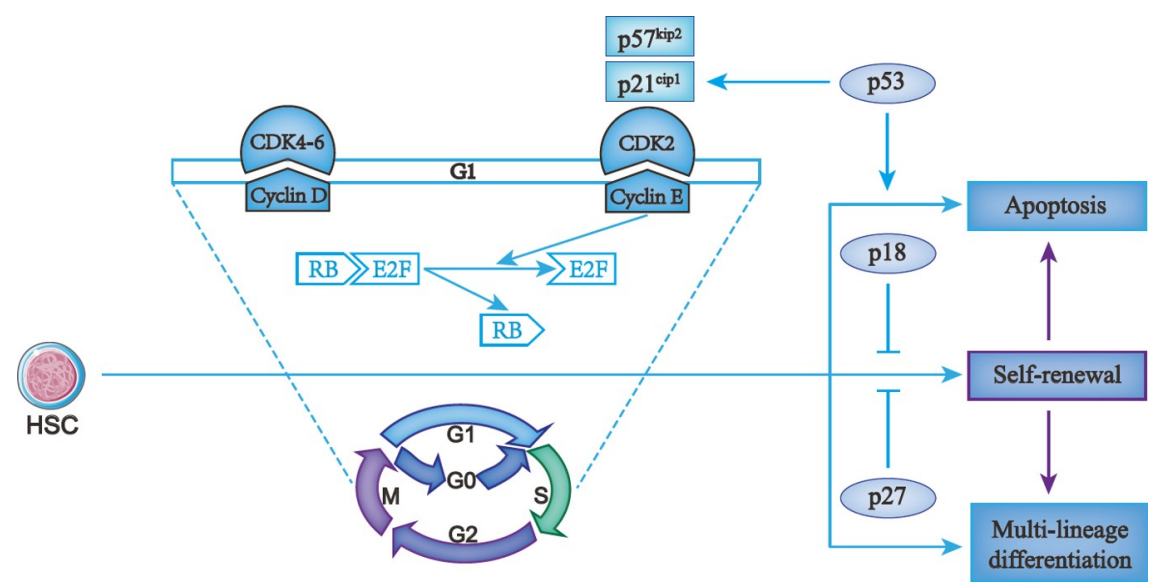

Figure 4 Schematic diagram of the precise mode of cell cycle regulation that is essential for HSC maintenance.

\section{R: Rest (quiescence)}

ASCs are considered resistant to various stimuli because they undergo prolonged periods of quiescence, referred as a state of reversible cell cycle arrest (Cheng, 2008). Quiescent ASCs have exited the cell cycle and entered $\mathrm{G}_{0}$ but can reenter the cell cycle in response to certain stimuli, while terminally differentiated cells in $\mathrm{G}_{0}$ are irreversibly arrested (van Velthoven and Rando, 2019). Recent studies have shown that the balance between quiescence and proliferation is strictly regulated by collaborative interactions between intrinsic and extrinsic signals to avoid excessive cell growth and exhaustion (Cho et al., 2019). Here, we highlight the regulatory mechanism by which ASCs remain quiescent and re-enter the cell cycle.

\section{Cell cycle regulation}

HSCs are relatively quiescent as they do not respond to many growth factors that affect hematopoietic progenitor cell populations (Cheng and Scadden, 2002). It is estimated that dormant murine HSCs divide only five times during their lifetime (Wilson et al., 2008). Such restriction of cell cycle progression is a vital part of the maintenance of cellular quiescence. Among the cyclin-dependent kinase inhibitors (CKIs) that control the $\mathrm{G}_{1}$ phase, p18 and p27 are the only negative regulators of HSC self-renewal, and $\mathrm{p} 18$ is a more potent inhibitor than $\mathrm{p} 27$ in murine models. A p18 deficiency promotes HSC expansion in long-term culture, and deleting the $\mathrm{p} 18$ gene induces self-renewing division of HSCs in vitro (Gao et al., 2015; Hao et al., 2016). Retinoblastoma protein (RB), a suppressor of the E2F transcription factor, is involved in the highly conserved RB-E2F signaling pathway and plays a key role in mediating the $\mathrm{G}_{1} / \mathrm{S}$ transition. Knockout of RB proteins not only induced excessive proliferation of HSCs, but also impaired their long-term capacity to reconstruct the hematopoietic system (Viatour et al.,
2008). p57 is the most abundant member of the CKI family in quiescent HSCs, and p57-deficient HSCs showed a reduction in the proportion of cells in $\mathrm{G}_{0}$ phase. Maintenance of quiescence was defective in p57-deficient HSCs due to a decrease in phosphorylated RB protein (Matsumoto et al., 2011). The tumor suppressor protein p53 activates the expression of $\mathrm{p} 21$, which is a key event in cell cycle arrest at the $\mathrm{G}_{1} / \mathrm{S}$ checkpoint in response to DNA damage (Figure 4). Depletion of p53 in HSCs promotes exit from the quiescent state and entry into the cell cycle, suggesting that p53 is essential for maintaining HSCs in the resting state (Liu et al., 2009).

\section{Metabolic regulation}

Quiescent HSCs share similarly altered metabolic requirements, such as reduced protein synthesis and mRNA levels. Deletion of phosphatase and tensin homolog deleted on chromosome ten (PTEN) in HSCs increased protein synthesis rates and forced HSCs to exit quiescence, ultimately leading to depletion of the stem cell pool (Signer et al., 2014). The energy consumption of quiescent stem cells is reduced by maintaining protein synthesis, which is an energy-consuming process, at a minimum level to meet their metabolic requirements (Buttgereit and Brand, 1995). Quiescent HSCs tend to use glycolysis and fatty acid energy metabolism to satisfy their energy demands, while their activated counterparts rely on oxidative phosphorylation (Simsek et al., 2010). Mitochondrial respiration rates in quiescent cells depend on the transport of fatty acids to mitochondria for $\beta$-oxidation (Wei et al., 2018). A possible reason why quiescent HSCs undergo preferential mitochondrial fatty acid $\beta$-oxidation is that this process generates predominantly reduced nicotinamide adenine nucleotide phosphate (NADPH), which is crucial for sustaining the homeostasis of cellular oxidation-reduction reactions via the glutathione reductase system (Mohammad et 
al., 2019). The reliance on glycolysis shields quiescent HSCs from ROS in a hypoxic environment. High ROS levels lead to HSC exhaustion and their exit from quiescence (Itkin et al., 2016). The metabolic preference for glycolysis in quiescent HSCs appears to protect HSCs from ROS production and has also been observed in other ASCs. This reliance on glycolysis implies the existence of an important but unexplained role for this metabolic pathway in quiescent ASCs (Coller, 2019).

\section{Gene expression profiling}

Transcriptional profile analysis of quiescent HSCs has revealed common gene expression characteristics. Compared with activated stem cells, genes involved in proliferation, mitochondrial function, and cell cycle progression were downregulated in quiescent HSCs. In contrast, genes involved in autophagy pathways, such as PTEN-induced putative kinase 1 (PINK1) and various transcriptional regulators, with known functions in stem cell fate determination, were upregulated in quiescent HSCs (Cho et al., 2019). Since undivided quiescent cells cannot dilute the effects of unwanted cell fragments and the accumulation of harmful or dysfunctional cellular components through the process of cell division, autophagy is critical to the maintenance of this population. In addition, autophagy in HSCs regulates ROS levels and limits oxidative damage by removing abnormal mitochondria (Guan et al., 2013; Mortensen et al., 2011). Aged HSCs exhibit a decline in autophagy and show epigenetic alterations leading to loss of quiescence and myeloid-biased differentiation (Ho et al., 2017). Furthermore, knockdown of CCCTC-binding factor restrained LT-HSCs from exiting quiescence, indicating that the transition of human HSCs from quiescence to the activated state is regulated by dynamic $3 \mathrm{D}$ genome rearrangements (Takayama et al., 2021).

\section{Niche factors}

Niche components also influence the cell cycle status of HSCs (Cheung and Rando, 2013). There are two proposed niches in the bone marrow, namely the endosteal niche and the perivascular niche. Quiescent HSCs were once thought to be located in the endosteal niche, although this has been disproved with the development of new techniques. Bone marrow imaging revealed the heterogeneity of perivascular niches, including sinusoidal niches with $\mathrm{Lepr}^{+}$stromal cells and arteriolar niches with $\mathrm{NG}^{+}$pericytes. Depletion of $\mathrm{NG}_{2}{ }^{+}$periarteriolar cells forced HSCs into cell cycle, demonstrating that cycling HSCs are preferentially located near the sinusoidal niches, whereas arteriolar niches are vital to the maintenance of HSC quiescence (Kunisaki et al., 2013; Szade et al., 2018). Sinusoidal and arteriolar niches differ in their permeability to plasma, which affects the ROS levels of neighboring HSCs. Quiescent HSCs localize adjacent to the less permeable arterioles with lower ROS levels, whereas active HSCs located near the more permeable sinusoids have higher ROS levels and increased differentiation (Pinho and Frenette, 2019). Schwann cells of autonomic nerves also contribute to the maintenance of HSC quiescence and their loss increases cycling HSCs by activating latent TGF- $\beta$ (Figure 2) (Blank and Karlsson, 2015).

\section{Re-entry into the cell cycle}

Although quiescent stem cells are transcriptionally and metabolically less active than other activated stem cells and downstream progenitors, various mechanisms allow their rapid entry into the cell cycle in response to different stimuli (van Velthoven and Rando, 2019). The balance of epigenetic DNA modifications can either activate or repress gene expression. HSC chromatin domains display both the repressive $\mathrm{H} 3 \mathrm{~K} 27 \mathrm{me} 3$ marker and the permissive $\mathrm{H} 3 \mathrm{~K} 4 \mathrm{me} 3$ marker. Genes in quiescent HSCs can be activated by removing the repressive $\mathrm{H} 3 \mathrm{~K} 27 \mathrm{me} 3$ or silenced by removing the activating $\mathrm{H} 3 \mathrm{~K} 4 \mathrm{me} 3$, resulting in changes in gene expression during lineage commitment (Cui et al., 2009). These results suggest that chromatin methylation plays a vital role in restricting differentiation and maintaining stem cells in the quiescent state (Cho et al., 2019). Furthermore, the presence of lineage-restricted transcripts in quiescent stem cells along with the absence of their corresponding protein products indicate that post-transcriptional regulatory mechanisms, such as that mediated by microRNAs, also play a key role in maintaining quiescence (Carrelha et al., 2018).

ASCs have evolved a complicated network to regulate quiescence entry, maintenance, and exit. Although quiescent ASCs avoid accumulation of mutations by evading mitosis, the diverse biological impacts of quiescence should not be disregarded (Sagot and Laporte, 2019). Quiescent HSCs express low levels of DNA damage repair genes, and accumulated DNA damage is repaired more efficiently after entering the cell cycle. DNA double-strand breaks in quiescent HSCs are repaired by non-homologous end joining (NHEJ) rather than homologous recombination (HR), which only occurs in proliferating cells. However, NHEJ is more prone to error and probably causes insertions and deletions (INDELs), thus reducing the ability of quiescent stem cells to maintain genomic integrity (Mohrin et al., 2010). Our ability to understand how the numerous mechanisms integrate to regulate quiescence is limited by the currently available culture systems that do not maintain ASCs in the quiescent state indefinitely. In vitro studies of ASCs are not considered to be optimal as the cells have to be removed from their niche and subsequently undergo alterations in response to changes in the environmental conditions (Calvi and Link, 2015). 
Therefore, isolated cells do not reflect the authentic state of resting ASCs in vivo (van Velthoven and Rando, 2019). Several strategies have been developed to avoid isolationinduced cellular changes, such as photoconversion cell labeling (Table 1).

\section{T: Trafficking}

Cellular trafficking capacity seems to be gradually acquired during embryonic development and is retained in some populations of ASCs, such as HSCs, neural stem cells (NSCs), and primordial germ cells (PGCs) (Magnon et al., 2011). Under homeostatic conditions, HSCs constitutively move out of the bone marrow niche toward the bloodstream in a circadian manner (Golan et al., 2018; Golan and Lapidot, 2019). Conversely, circulating HSCs can migrate into the bone marrow after intravascular injection through a process called homing, which is the first step in achieving long-term hematopoietic reconstruction in clinical transplantation (Dong et al., 2020a). Here, we explain how molecular and biochemical signals regulate HSC mobilization for homeostasis in adulthood.

\section{Homing and mobilization}

The process of HSC homing is initiated by the tethering and rolling of HSCs on bone marrow sinusoidal vessels resulting in their adherence to the endothelium (Magnon et al., 2011). LT-HSC homing is inhibited by an antibody that blocks the function of the laminin receptor integrin $\alpha 6$ chain, which is highly expressed in HSCs. Similar inhibition of LT-HSC homing is mediated by a function-blocking antibody against $\alpha 4$ integrin (Qian et al., 2006). HSC migration toward the bone marrow is also guided by chemoattractant signals, such as the chemokine $\mathrm{C}-\mathrm{X}-\mathrm{C}$ motif chemokine ligand 12 (CXCL12) and its receptor C-X-C motif chemokine receptor 4 (CXCR4). The binding of integrin $\alpha 4 \beta 1$ to its receptor, vascular cell adhesion molecule 1 (VCAM-1), is regulated by CXCL12 expression on the surface of endothelial cells and HSC homing is obstructed by blocking the $\alpha 4 \beta 1 /$ VCAM-1 or CXCR4/CXCL12 interactions (Papayannopoulou et al., 1995). CD26, a cell surface peptidase also known as dipeptidyl peptidase IV (DPPIV), is expressed on various cell types and cleaves the amino-terminal dipeptide of some chemokines, including CXCL12. Transplantation of $\mathrm{CD} 26^{-/-}$donor cells into lethally irradiated recipients made a greater contribution to the leukocytes in peripheral blood compared with transplantation of normal cells, indicating that endogenous CD26 expression on donor cells negatively regulates HSC homing (Figure 2) (Christopherson et al., 2004). These findings elucidate the cooperative roles of various cell adhesion molecules and chemoattractant signals in regulating the interactions between HSCs and the bone marrow vasculature. Furthermore, HSC homing is regulated by anchoring to PTN on sinusoidal endothelial cells, and PTN also modulates HSC retention in this niche (Himburg et al., 2012).

Despite retention signals from the bone marrow, a significant fraction of HSCs migrate to the blood circulatory system in a process known as mobilization. Circadian regulation of HSC egress from the bone marrow is controlled by a local and cyclical release of noradrenaline from local sympathetic nerve terminals. Rhythmic secretion of noradrenaline acts on the $\beta 3$ adrenergic receptor (Adr $\beta 3$ ), which is expressed on stromal cells, leading to the degradation of transcription factor $\mathrm{Sp} 1$ and downregulation of CXCL12 (Golan et al., 2018; Magnon and Frenette, 2008). Certain drugs have been exploited to enhance HSC mobilization for clinical transplantation. Various cytokines, such as granulocyte colony-stimulating factor (G-CSF) and chemokines, including IL-8, have been used to mobilize HSCs. For clinical purposes, HSCs are generally collected after mobilization into the circulation by G-CSF treatment rather than harvesting them directly from the bone marrow (Papayannopoulou and Scadden, 2008). In mouse models, a novel HSC mobilization regimen consisting of treatment with the CXCR2 agonist GRO $\beta$, and the CXCR4 antagonist AMD3100, results in peak mobilization within $15 \mathrm{~min}$, which is equal to the effect of the G-CSF regimen used

Table 1 Strategies to study quiescent stem cells for in vivo analysis

\begin{tabular}{|c|c|c|c|}
\hline Strategies & Acquired information & Inadequacies & References \\
\hline Photoconversion cell labeling & Gene expression profiles & $\begin{array}{l}\text { Inaccurate native profiles in the ab- } \\
\text { sence of optimized protocols }\end{array}$ & (Morrison et al., 2015) \\
\hline 4-Thiouracil (4tU) labeling & Dynamics of RNA synthesis & $\begin{array}{l}\text { Large proportion of unwanted labeled } \\
\text { nascent rRNA transcripts }\end{array}$ & (van Velthoven et al., 2017) \\
\hline Ribosome profiling & $\begin{array}{c}\text { Number and location of ribosomes on } \\
\text { mRNAs }\end{array}$ & $\begin{array}{l}\text { Interpretation complicated by some } \\
\text { nucleases with sequence specificities }\end{array}$ & (McGlincy and Ingolia, 2017) \\
\hline $\begin{array}{l}\text { Stable isotope labeling of amino acids } \\
\text { in mammals (SILAM) }\end{array}$ & Protein turnover and lifetimes & $\begin{array}{l}\text { High cost of isotopically labeled } \\
\text { mouse food }\end{array}$ & (Alevra et al., 2019) \\
\hline $\begin{array}{c}\text { Proximity-dependent biotinylation } \\
\text { coupled to mass spectrometry (PDB- } \\
\text { MS) }\end{array}$ & $\begin{array}{l}\text { Proximity among proteins and protein- } \\
\text { nucleic acid interactions }\end{array}$ & $\begin{array}{l}\text { Uncertainty relating to whether pro- } \\
\text { teins are physically interacting or } \\
\text { simply localized to the same area }\end{array}$ & (Samavarchi-Tehrani et al., 2020) \\
\hline
\end{tabular}


clinically in terms of the numbers of HSCs mobilized. Moreover, this new regimen has been used to achieve higher engraftment efficiency and more rapid hematopoietic recovery than the regimen of mobilization by G-CSF, suggesting a new potential clinical program for rapid HSC mobilization (Hoggatt et al., 2018). Nociceptor neurons promote G-CSF-induced HSC mobilization. In mouse models the ingestion of food containing capsaicin enhances the mobilization of HSCs dramatically via activation of nociceptive neurons, thus indicating the therapeutic potential of drugs targeting the nociceptive nervous system for HSC mobilization (Figure 2) (Gao et al., 2021). HSC mobilization is also regulated by hormones, such as pituitary glucocorticoids, which impair HSC mobilization in response to G-CSF (Pierce et al., 2017). Furthermore, studies in zebrafish and mouse models have shown that prostaglandins mobilize HSCs from the bone marrow to the circulation, where HSCs can be collected for transplantation (Hoggatt et al., 2013; North et al., 2007).

The cellular offspring of HSCs, namely leukocytes, impact HSC trafficking and related regulatory mechanisms. Many of the pathways that regulate HSC trafficking to the circulation, such as CXCL12 signaling, also regulate leukocyte trafficking (Lucas, 2019). The Hidalgo team found that the egress of HSCs into the circulation was reduced when neutrophils were depleted, and CXCR4 deletion interrupted the recruitment of aged neutrophils to the bone marrow (Casanova-Acebes et al., 2013). The Lin team showed that donor HSCs persisted in recipients for $30 \mathrm{~d}$ after allogeneic transplantation of HLA-mismatched HSCs in the absence of immunosuppression, indicating that the bone marrow niche was immune privileged. Furthermore, image analyses showed that the donor HSCs were surrounded by forkhead box-P3 $\left(\right.$ Foxp $^{+}{ }^{+}$) regulatory T cells (Tregs) (Fujisaki et al., 2011). The CD39 cell surface ectoenzyme on niche Tregs generates extracellular adenosine. In transplanted mice, both CD39 deletion and adenosine receptor antagonist treatment decrease allogeneic HSC engraftment, suggesting that the function of nice Tregs is adenosine-dependent. Transfer of niche Tregs in a murine model significantly increased allogenic HSC engraftment (Hirata et al., 2018). The Levesque team reported that G-CSF treatment for HSC mobilization caused the loss of a population of macrophages intimately associated with endosteal cells in a process that correlated with CXCL12 downregulation by the endosteal stromal cells. Crosstalk between macrophages and niche components controls the generation of CXCL12, which maintains HSCs in their niches (Ludin et al., 2012; Winkler et al., 2010). Murine bone marrow DCs are perivascular, and ablation of conventional DCs enhances the ability of G-CSF to mobilize HSCs. Bone marrow DCs regulate HSC trafficking partially through the regulation of vascular permeability and sinusoidal CXCR2 signaling (Zhang et al., 2019).
Studies have demonstrated that ASC trafficking is also regulated by mechanical signals. Low shear stress $(0.2 \mathrm{~Pa})$ induces trafficking of mesenchymal stem cells (MSCs) through mitogen-activated protein kinase (MAPK) signaling pathways. Furthermore, shear stress upregulates the secretion of CXCL12, which stimulates the expression of its receptor CXCR4 in MSCs (Yuan et al., 2013). Cell trafficking through tissue depends on a balance between cell deformability and physical tissue constraints. HSC mobilization from the niche involves stromal upregulation of proteolytic enzymes, such as matrix metalloproteinase 9 (MMP-9) and cysteine protease cathepsin $\mathrm{K}$ (Cat $\mathrm{K})$, resulting in proteolytic segmentation of CXCL12 and VCAM-1 and loosening of the adhesion between stromal cells (Heissig et al., 2002; Kollet et al., 2006). Ptpn 21 knockout dramatically increased the number of HSCs in the peripheral blood and the spleen and enhanced G-CSF-induced HSC mobilization through reduction in the intracellular tension and cell stiffness, leading to the impaired retention of HSCs (Ni et al., 2019).

\section{Trafficking within the bone marrow}

In addition to movement in and out, HSCs also migrate within the bone marrow (Tokoyoda et al., 2004). Most quiescent HSCs tend to reside in the endosteal region of the bone marrow, where osteoblasts may provide essential growth factors and regulatory signals (Calvi et al., 2003; Mazo et al., 2011). Osteoblasts and osteoclasts form unique units associated with a local increase in free calcium ions. HSCs respond to variations in extracellular calcium ion concentration through the calcium ion receptor $(\mathrm{CaR})$, and HSC engraftment is defective in following transplantation in the absence of the CaR (Adams et al., 2006). After maturation, HSC quiescence is gradually lost after maturation and the cells migrate toward the center of the bone marrow to begin proliferating (Heissig et al., 2002). The migration of HSCs toward specialized niches during differentiation may account for the distinct distribution of myeloid and lymphoid populations in the bone marrow (Mazo et al., 2011).

\section{Trafficking in other tissues}

HSCs can also migrate into and out of peripheral tissues. Tissue damage facilitates HSC migration into sites of injury. After myocardial infarction (MI), the activated sympathetic nervous system triggers HSC trafficking from the bone marrow to the spleen, inducing enhanced extramedullary myelopoiesis. Studies have also shown that the mRNA level of C-C chemokine ligand 2 (CCL2) is elevated in endothelial cells following MI, suggesting that CCL2 binds to the functional receptor $\mathrm{C}-\mathrm{C}$ chemokine receptor type 2 (CCR2) to mobilize CCR2 ${ }^{+}$HSCs from their niche (Dutta et al., 2015). In experimental murine models of acute myeloid 
leukemia, spleen volume and splenic HSC numbers increase with disease progression. This extramedullary hematopoiesis aligns with the increased numbers of splenic endothelial cells, which probably support the formation of the vascular niche to maintain HSCs in their relocation to the spleen (Duarte et al., 2018). However, the pathways regulating the egress of HSCs from tissues have not yet been fully elucidated. HSCs arrive at peripheral organs via the bloodstream and leave in the lymphatic circulation (Laird et al., 2008). The egress of HSCs from peripheral tissues is related to their exit from secondary lymphoid organs into the lymph, which depends on a signaling pathway involving sphingosine-1 phosphate (S1P) and S1P receptors (Massberg and von Andrian, 2006). S1P levels are high in the lymph, but low in tissues due to degradation by S1P lyase, thus forming a distinct gradient along which the HSCs leave peripheral organs. Stress signals induced by the administration of a tolllike receptor 4 (TLR4) agonist reduce S1P receptor 1 expression on HSCs, leading to prolonged retention in peripheral organs (Mazo et al., 2011).

The steady recirculation of HSCs is vital for homeostasis; however, many aspects of this process remain to be clarified. The mechanisms that control HSC trafficking in the bone marrow parenchyma remain unclear. Analysis of HSC migration in vivo usually requires large numbers of cells, which are difficult to obtain; therefore, it is hard to distinguish between HSCs and hematopoietic progenitor cells when studying trafficking. New techniques are needed to dissect the mechanisms of this process and identify new stem cell targeted therapies.

\section{Concluding remarks}

Research into ASCs is showing great promise for the treatment of various diseases with the development of innovative medical products and the advancement of personalized medicine. The principal biological features of this fascinating cell type constitute an interesting "SMART" model and require further investigation to facilitate precise manipulation of stem cells for the treatment of a broader spectrum of diseases. Due to their scarcity in the tissues, considerable efforts are required to identify and purify ASCs. It is undeniable that many scientific hurdles remain to be overcome before therapeutic applications of ASCs reach their full potential. Single cell multi-omics sequencing technologies combined with analytical techniques and other highthroughput technologies can serve as powerful tools, and these developing methods provide the opportunity to profile the molecular state of various adult stem cells in health and disease. Identification of the cell state will contribute to the classification of disease mechanisms as well as the development of novel diagnostic and therapeutic strategies. What lies ahead for the use of ASCs is inspiring, and a better understanding of the SMART features will allow the development of more effective and much safer therapeutic products in this promising area. While there is still a great deal to learn regarding the biology of this SMART model, we may also exploit the five SMART features to develop measurable parameters to ensure the quality of stem cells for therapeutic purposes.

Compliance and ethics The author(s) declare that they have no conflict of interest.

Acknowledgements This work was supported by the Ministry of Science and Technology of China (2016YFA0100600, 2017YFA0103400, 2020YFE0203000), the National Natural Science Foundation of China (81922002, 81730006, 81890990, 81870086, 82070112), the CAMS Initiative for Innovative Medicine (2017-I2M-3-009, 2016-I2M-1-017), and Distinguished Young Scholars of Tianjin (19JCJQJC63400).

\section{References}

Adams, G.B., Chabner, K.T., Alley, I.R., Olson, D.P., Szczepiorkowski, Z. M., Poznansky, M.C., Kos, C.H., Pollak, M.R., Brown, E.M., and Scadden, D.T. (2006). Stem cell engraftment at the endosteal niche is specified by the calcium-sensing receptor. Nature 439, 599-603.

Alevra, M., Mandad, S., Ischebeck, T., Urlaub, H., Rizzoli, S.O., and Fornasiero, E.F. (2019). A mass spectrometry workflow for measuring protein turnover rates in vivo. Nat Protoc 14, 3333-3365.

Ali, F., Taresh, S., Al-Nuzaily, M., Mok, P.L., Ismail, A., and Ahmad, S. (2016). Stem cells differentiation and probing their therapeutic applications in hematological disorders: a critical review. Eur Rev Med Pharmacol Sci 20, 4390-4400.

Allsopp, R.C., Cheshier, S., and Weissman, I.L. (2001). Telomere shortening accompanies increased cell cycle activity during serial transplantation of hematopoietic stem cells. J Exp Med 193, 917-924.

Asada, N., Kunisaki, Y., Pierce, H., Wang, Z., Fernandez, N.F., Birbrair, A., Ma'ayan, A., and Frenette, P.S. (2017). Differential cytokine contributions of perivascular haematopoietic stem cell niches. Nat Cell Biol 19, 214-223.

Bai, T., Li, J., Sinclair, A., Imren, S., Merriam, F., Sun, F., O’Kelly, M.B., Nourigat, C., Jain, P., Delrow, J.J., et al. (2019). Expansion of primitive human hematopoietic stem cells by culture in a zwitterionic hydrogel. Nat Med 25, 1566-1575.

Barker, N., van Es, J.H., Kuipers, J., Kujala, P., van den Born, M., Cozijnsen, M., Haegebarth, A., Korving, J., Begthel, H., Peters, P.J., et al. (2007). Identification of stem cells in small intestine and colon by marker gene Lgr5. Nature 449, 1003-1007.

Bergmann, A., and Steller, H. (2010). Apoptosis, stem cells, and tissue regeneration. Sci Signal 3, re8.

Beslu, N., Krosl, J., Laurin, M., Mayotte, N., Humphries, K.R., and Sauvageau, G. (2004). Molecular interactions involved in HOXB4induced activation of HSC self-renewal. Blood 104, 2307-2314.

Bhardwaj, G., Murdoch, B., Wu, D., Baker, D.P., Williams, K.P., Chadwick, K., Ling, L.E., Karanu, F.N., and Bhatia, M. (2001). Sonic hedgehog induces the proliferation of primitive human hematopoietic cells via BMP regulation. Nat Immunol 2, 172-180.

Bieging, K.T., Mello, S.S., and Attardi, L.D. (2014). Unravelling mechanisms of p53-mediated tumour suppression. Nat Rev Cancer 14, 359-370.

Blank, U., and Karlsson, S. (2015). TGF- $\beta$ signaling in the control of hematopoietic stem cells. Blood 125, 3542-3550.

Blasco, M.A. (2005). Telomeres and human disease: ageing, cancer and beyond. Nat Rev Genet 6, 611-622. 
Boitano, A.E., Wang, J., Romeo, R., Bouchez, L.C., Parker, A.E., Sutton, S. E., Walker, J.R., Flaveny, C.A., Perdew, G.H., Denison, M.S., et al. (2010). Aryl hydrocarbon receptor antagonists promote the expansion of human hematopoietic stem cells. Science 329, 1345-1348.

Borggrefe, T., Lauth, M., Zwijsen, A., Huylebroeck, D., Oswald, F., and Giaimo, B.D. (2016). The Notch intracellular domain integrates signals from Wnt, Hedgehog, TGF $\beta / B M P$ and hypoxia pathways. Biochim Biophys Acta 1863, 303-313.

Buttgereit, F., and Brand, M.D. (1995). A hierarchy of ATP-consuming processes in mammalian cells. Biochem J 312, 163-167.

Calvi, L.M., and Link, D.C. (2015). The hematopoietic stem cell niche in homeostasis and disease. Blood 126, 2443-2451.

Calvi, L.M., Adams, G.B., Weibrecht, K.W., Weber, J.M., Olson, D.P., Knight, M.C., Martin, R.P., Schipani, E., Divieti, P., Bringhurst, F.R., et al. (2003). Osteoblastic cells regulate the haematopoietic stem cell niche. Nature 425, 841-846.

Carrelha, J., Meng, Y., Kettyle, L.M., Luis, T.C., Norfo, R., Alcolea, V., Boukarabila, H., Grasso, F., Gambardella, A., Grover, A., et al. (2018). Hierarchically related lineage-restricted fates of multipotent haematopoietic stem cells. Nature 554, 106-111.

Casanova-Acebes, M., Pitaval, C., Weiss, L.A., Nombela-Arrieta, C., Chèvre, R., A-González, N., Kunisaki, Y., Zhang, D., van Rooijen, N., Silberstein, L.E., et al. (2013). Rhythmic modulation of the hematopoietic niche through neutrophil clearance. Cell 153, 1025 1035.

Challen, G.A., Boles, N.C., Chambers, S.M., and Goodell, M.A. (2010). Distinct hematopoietic stem cell subtypes are differentially regulated by TGF- $\beta 1$. Cell Stem Cell 6, 265-278.

Chen, J.Y., Miyanishi, M., Wang, S.K., Yamazaki, S., Sinha, R., Kao, K.S., Seita, J., Sahoo, D., Nakauchi, H., and Weissman, I.L. (2016). Hoxb5 marks long-term haematopoietic stem cells and reveals a homogenous perivascular niche. Nature 530, 223-227.

Cheng, H., Sun, G., and Cheng, T. (2018). Hematopoiesis and microenvironment in hematological malignancies. Cell Regen 7, 22-26.

Cheng, H., Zheng, Z., and Cheng, T. (2020). New paradigms on hematopoietic stem cell differentiation. Protein Cell 11, 34-44.

Cheng, T. (2008). Toward 'SMART' stem cells. Gene Ther 15, 67-73.

Cheng, T., and Scadden, D.T. (2002). Cell cycle entry of hematopoietic stem and progenitor cells controlled by distinct cyclin-dependent kinase inhibitors. Int J Hematol 75, 460-465.

Cheng, Y., Luo, H., Izzo, F., Pickering, B.F., Nguyen, D., Myers, R., Schurer, A., Gourkanti, S., Brüning, J.C., Vu, L.P., et al. (2019). m A RNA methylation maintains hematopoietic stem cell identity and symmetric commitment. Cell Rep 28, 1703-1716.e6.

Cheung, T.H., and Rando, T.A. (2013). Molecular regulation of stem cell quiescence. Nat Rev Mol Cell Biol 14, 329-340.

Cho, I.J., Lui, P.P.W., Obajdin, J., Riccio, F., Stroukov, W., Willis, T.L., Spagnoli, F., and Watt, F.M. (2019). Mechanisms, hallmarks, and implications of stem cell quiescence. Stem Cell Rep 12, 1190-1200.

Christopherson, K.W., Hangoc, G., Mantel, C.R., and Broxmeyer, H.E. (2004). Modulation of hematopoietic stem cell homing and engraftment by CD26. Science $305,1000-1003$.

Clevers, H. (2015). What is an adult stem cell? Science 350, 1319-1320.

Codispoti, B., Makeeva, I., Sied, J., Benincasa, C., Scacco, S., and Tatullo, M. (2019). Should we reconsider the apoptosis as a strategic player in tissue regeneration? Int J Biol Sci 15, 2029-2036.

Cohen, S., Roy, J., Lachance, S., Delisle, J.S., Marinier, A., Busque, L., Roy, D.C., Barabé, F., Ahmad, I., Bambace, N., et al. (2020). Hematopoietic stem cell transplantation using single UM171expanded cord blood: a single-arm, phase 1-2 safety and feasibility study. Lancet Haematol 7, e134-e145.

Coller, H.A. (2019). The paradox of metabolism in quiescent stem cells. FEBS Lett 593, 2817-2839.

Collins, K., and Mitchell, J.R. (2002). Telomerase in the human organism. Oncogene 21, 564-579.

Cui, K., Zang, C., Roh, T.Y., Schones, D.E., Childs, R.W., Peng, W., and Zhao, K. (2009). Chromatin signatures in multipotent human hematopoietic stem cells indicate the fate of bivalent genes during differentiation. Cell Stem Cell 4, 80-93.

de Lau, W., Peng, W.C., Gros, P., and Clevers, H. (2014). The R-spondin/ Lgr5/Rnf43 module: regulator of Wnt signal strength. Genes Dev 28, 305-316

DiMascio, L., Voermans, C., Uqoezwa, M., Duncan, A., Lu, D., Wu, J., Sankar, U., and Reya, T. (2007). Identification of adiponectin as a novel hemopoietic stem cell growth factor. J Immunol 178, 3511-3520.

Ding, L., Saunders, T.L., Enikolopov, G., and Morrison, S.J. (2012). Endothelial and perivascular cells maintain haematopoietic stem cells. Nature 481, 457-462.

Domen, J., Cheshier, S.H., and Weissman, I.L. (2000). The role of apoptosis in the regulation of hematopoietic stem cells. J Exp Med 191, 253-264.

Dong, F., Cheng, H., Ema, H., and Cheng, T. (2020a). Probing the fate of transplanted hematopoietic stem cells: is the combinational approach "FIT" for purpose? Sci China Life Sci 63, 1755-1758.

Dong, F., Hao, S., Zhang, S., Zhu, C., Cheng, H., Yang, Z., Hamey, F.K., Wang, X., Gao, A., Wang, F., et al. (2020b). Differentiation of transplanted haematopoietic stem cells tracked by single-cell transcriptomic analysis. Nat Cell Biol 22, 630-639.

Duarte, D., Hawkins, E.D., Akinduro, O., Ang, H., De Filippo, K., Kong, I. Y., Haltalli, M., Ruivo, N., Straszkowski, L., Vervoort, S.J., et al. (2018). Inhibition of endosteal vascular niche remodeling rescues hematopoietic stem cell loss in AML. Cell Stem Cell 22, 64-77.e6.

Dulak, J., Szade, K., Szade, A., Nowak, W., and Józkowicz, A. (2015). Adult stem cells: hopes and hypes of regenerative medicine. Acta Biochim Pol 62, 329-337.

Dutta, P., Sager, H.B., Stengel, K.R., Naxerova, K., Courties, G., Saez, B., Silberstein, L., Heidt, T., Sebas, M., Sun, Y., et al. (2015). Myocardial infarction activates $\mathrm{CCR} 2^{+}$hematopoietic stem and progenitor cells. Cell Stem Cell 16, 477-487.

Edlich, F. (2018). BCL-2 proteins and apoptosis: Recent insights and unknowns. Biochem Biophys Res Commun 500, 26-34.

Fares, I., Chagraoui, J., Gareau, Y., Gingras, S., Ruel, R., Mayotte, N., Csaszar, E., Knapp, D.J.H.F., Miller, P., Ngom, M., et al. (2014). Pyrimidoindole derivatives are agonists of human hematopoietic stem cell self-renewal. Science 345, 1509-1512.

Flores, I., Benetti, R., and Blasco, M.A. (2006). Telomerase regulation and stem cell behaviour. Curr Opin Cell Biol 18, 254-260.

Fujisaki, J., Wu, J., Carlson, A.L., Silberstein, L., Putheti, P., Larocca, R., Gao, W., Saito, T.I., Lo Celso, C., Tsuyuzaki, H., et al. (2011). In vivo imaging of Treg cells providing immune privilege to the haematopoietic stem-cell niche. Nature 474, 216-219.

Gao, X., Zhang, D., Xu, C., Li, H., Caron, K.M., and Frenette, P.S. (2021). Nociceptive nerves regulate haematopoietic stem cell mobilization. Nature 589, 591-596.

Gao, Y., Yang, P., Shen, H., Yu, H., Song, X., Zhang, L., Zhang, P., Cheng, H., Xie, Z., Hao, S., et al. (2015). Small-molecule inhibitors targeting INK4 protein p18 ${ }^{\text {INK4C }}$ enhance ex vivo expansion of haematopoietic stem cells. Nat Commun 6, 6328.

Garcia-Lavandeira, M., Diaz-Rodriguez, E., Bahar, D., Garcia-Rendueles, A.R., Rodrigues, J.S., Dieguez, C., and Alvarez, C.V. (2015). Pituitary cell turnover: from adult stem cell recruitment through differentiation to death. Neuroendocrinology 101, 175-192.

Golan, K., Kumari, A., Kollet, O., Khatib-Massalha, E., Subramaniam, M. D., Ferreira, Z.S., Avemaria, F., Rzeszotek, S., García-García, A., Xie, S., et al. (2018). Daily onset of light and darkness differentially controls hematopoietic stem cell differentiation and maintenance. Cell Stem Cell 23, 572-585.e7.

Golan, K., and Lapidot, T. (2019). Daily light-and-darkness onset regulates mouse hematopoietic stem cells. Blood Adv 3, 704.

Guan, J.L., Simon, A.K., Prescott, M., Menendez, J.A., Liu, F., Wang, F., Wang, C., Wolvetang, E., Vazquez-Martin, A., and Zhang, J. (2013). Autophagy in stem cells. Autophagy 9, 830-849.

Hao, S., Chen, C., and Cheng, T. (2016). Cell cycle regulation of hematopoietic stem or progenitor cells. Int J Hematol 103, 487-497. 
Heissig, B., Hattori, K., Dias, S., Friedrich, M., Ferris, B., Hackett, N.R., Crystal, R.G., Besmer, P., Lyden, D., Moore, M.A.S., et al. (2002). Recruitment of stem and progenitor cells from the bone marrow niche requires MMP-9 mediated release of kit-ligand. Cell 109, 625-637.

Himburg, H.A., Muramoto, G.G., Daher, P., Meadows, S.K., Russell, J.L., Doan, P., Chi, J.T., Salter, A.B., Lento, W.E., Reya, T., et al. (2010). Pleiotrophin regulates the expansion and regeneration of hematopoietic stem cells. Nat Med 16, 475-482.

Himburg, H.A., Harris, J.R., Ito, T., Daher, P., Russell, J.L., Quarmyne, M., Doan, P.L., Helms, K., Nakamura, M., Fixsen, E., et al. (2012). Pleiotrophin regulates the retention and self-renewal of hematopoietic stem cells in the bone marrow vascular niche. Cell Rep 2, 964-975.

Hirata, Y., Furuhashi, K., Ishii, H., Li, H.W., Pinho, S., Ding, L., Robson, S. C., Frenette, P.S., and Fujisaki, J. (2018). CD150 $0^{\text {high }}$ bone marrow Tregs maintain hematopoietic stem cell quiescence and immune privilege via adenosine. Cell Stem Cell 22, 445-453.e5.

Ho, T.T., Warr, M.R., Adelman, E.R., Lansinger, O.M., Flach, J., Verovskaya, E.V., Figueroa, M.E., and Passegué, E. (2017). Autophagy maintains the metabolism and function of young and old stem cells. Nature 543, 205-210.

Hoggatt, J., Mohammad, K.S., Singh, P., Hoggatt, A.F., Chitteti, B.R., Speth, J.M., Hu, P., Poteat, B.A., Stilger, K.N., Ferraro, F., et al. (2013). Differential stem- and progenitor-cell trafficking by prostaglandin E2. Nature 495, 365-369.

Hoggatt, J., Singh, P., Tate, T.A., Chou, B.K., Datari, S.R., Fukuda, S., Liu, L., Kharchenko, P.V., Schajnovitz, A., Baryawno, N., et al. (2018). Rapid mobilization reveals a highly engraftable hematopoietic stem cell. Cell 172, 191-204.e10.

Hu, L., Zhang, Y., Miao, W., and Cheng, T. (2019). Reactive oxygen species and Nrf2: Functional and transcriptional regulators of hematopoiesis. Oxid Med Cell Longev 2019, 1-11.

Itkin, T., Ludin, A., Gradus, B., Gur-Cohen, S., Kalinkovich, A., Schajnovitz, A., Ovadya, Y., Kollet, O., Canaani, J., Shezen, E., et al. (2012). FGF-2 expands murine hematopoietic stem and progenitor cells via proliferation of stromal cells, c-Kit activation, and CXCL12 downregulation. Blood 120, 1843-1855.

Itkin, T., Gur-Cohen, S., Spencer, J.A., Schajnovitz, A., Ramasamy, S.K., Kusumbe, A.P., Ledergor, G., Jung, Y., Milo, I., Poulos, M.G., et al. (2016). Distinct bone marrow blood vessels differentially regulate haematopoiesis. Nature 532, 323-328.

Ito, K., and Ito, K. (2018). Hematopoietic stem cell fate through metabolic control. Exp Hematol 64, 1-11.

Kikushige, Y., Yoshimoto, G., Miyamoto, T., Iino, T., Mori, Y., Iwasaki, H., Niiro, H., Takenaka, K., Nagafuji, K., Harada, M., et al. (2008). Human Flt3 is expressed at the hematopoietic stem cell and the granulocyte/ macrophage progenitor stages to maintain cell survival. J Immunol 180, 7358-7367.

Kollet, O., Dar, A., Shivtiel, S., Kalinkovich, A., Lapid, K., Sztainberg, Y., Tesio, M., Samstein, R.M., Goichberg, P., Spiegel, A., et al. (2006). Osteoclasts degrade endosteal components and promote mobilization of hematopoietic progenitor cells. Nat Med 12, 657-664.

Korinek, V., Barker, N., Moerer, P., van Donselaar, E., Huls, G., Peters, P.J., and Clevers, H. (1998). Depletion of epithelial stem-cell compartments in the small intestine of mice lacking Tcf-4. Nat Genet 19, 379-383.

Kunisaki, Y., Bruns, I., Scheiermann, C., Ahmed, J., Pinho, S., Zhang, D., Mizoguchi, T., Wei, Q., Lucas, D., Ito, K., et al. (2013). Arteriolar niches maintain haematopoietic stem cell quiescence. Nature 502, 637643.

Laird, D.J., von Andrian, U.H., and Wagers, A.J. (2008). Stem cell trafficking in tissue development, growth, and disease. Cell 132, 612630.

Laurenti, E., and Göttgens, B. (2018). From haematopoietic stem cells to complex differentiation landscapes. Nature 553, 418-426.

Lechman, E.R., Gentner, B., van Galen, P., Giustacchini, A., Saini, M., Boccalatte, F.E., Hiramatsu, H., Restuccia, U., Bachi, A., Voisin, V., et al. (2012). Attenuation of miR-126 activity expands HSC in vivo without exhaustion. Cell Stem Cell 11, 799-811.
Li, X., Zhang, T., Wilson, A., Amarachintha, S., Sertorio, M., and Pang, Q. (2015). Transcriptional profiling of Foxo3a and Fancd2 regulated genes in mouse hematopoietic stem cells. Genomics Data 4, 148-149.

Liu, Y., Elf, S.E., Miyata, Y., Sashida, G., Liu, Y., Huang, G., Di Giandomenico, S., Lee, J.M., Deblasio, A., Menendez, S., et al. (2009). p53 regulates hematopoietic stem cell quiescence. Cell Stem Cell 4, 3748.

Loeffler, D., Wehling, A., Schneiter, F., Zhang, Y., Müller-Bötticher, N., Hoppe, P.S., Hilsenbeck, O., Kokkaliaris, K.D., Endele, M., and Schroeder, T. (2019). Asymmetric lysosome inheritance predicts activation of haematopoietic stem cells. Nature 573, 426-429.

Lu, R., Czechowicz, A., Seita, J., Jiang, D., and Weissman, I.L. (2019). Clonal-level lineage commitment pathways of hematopoietic stem cells in vivo. Proc Natl Acad Sci USA 116, 1447-1456.

Lucas, D. (2017). The bone marrow microenvironment for hematopoietic stem cells. In: Birbrair, A., ed. Stem Cell Microenvironments and Beyond. Advances in Experimental Medicine and Biology. Cham: Springer. 5-18.

Lucas, D. (2019). Leukocyte trafficking and regulation of murine hematopoietic stem cells and their niches. Front Immunol 10, 387.

Ludin, A., Itkin, T., Gur-Cohen, S., Mildner, A., Shezen, E., Golan, K., Kollet, O., Kalinkovich, A., Porat, Z., D’Uva, G., et al. (2012). Monocytes-macrophages that express $\alpha$-smooth muscle actin preserve primitive hematopoietic cells in the bone marrow. Nat Immunol 13, 1072-1082.

Ludin, A., Gur-Cohen, S., Golan, K., Kaufmann, K.B., Itkin, T., Medaglia, C., Lu, X.J., Ledergor, G., Kollet, O., and Lapidot, T. (2014). Reactive oxygen species regulate hematopoietic stem cell self-renewal, migration and development, as well as their bone marrow microenvironment. Antioxid Redox Signal 21, 1605-1619.

Luo, M., Jeong, M., Sun, D., Park, H.J., Rodriguez, B.A.T., Xia, Z., Yang, L., Zhang, X., Sheng, K., Darlington, G.J., et al. (2015). Long noncoding RNAs control hematopoietic stem cell function. Cell Stem Cell $16,426-438$.

Maciejewski, J.P., and Risitano, A. (2003). Hematopoietic stem cells in aplastic anemia. Archives Med Res 34, 520-527.

Magnon, C., and Frenette, P.S. (2008). Hematopoietic stem cell trafficking. In: StemBook. Cambridge (MA): Harvard Stem Cell Institute.

Magnon, C., Lucas, D., and Frenette, P.S. (2011). Trafficking of stem cells. In: Filippi, M.D., and Geiger, H., eds. Stem Cell Migration. Methods in Molecular Biology (Methods and Protocols). New York: Humana Press. $3-24$.

Mantel, C.R., O'Leary, H.A., Chitteti, B.R., Huang, X.X., Cooper, S., Hangoc, G., Brustovetsky, N., Srour, E.F., Lee, M.R., Messina-Graham, S., et al. (2015). Enhancing hematopoietic stem cell transplantation efficacy by mitigating oxygen shock. Cell 161, 1553-1565.

Mao, A.S., and Mooney, D.J. (2015). Regenerative medicine: Current therapies and future directions. Proc Natl Acad Sci USA 112, 1445214459 .

Massberg, S., and von Andrian, U.H. (2006). Fingolimod and sphingosine1-phosphate-Modifiers of lymphocyte migration. N Engl J Med 355, 1088-1091.

Matsumoto, A., Takeishi, S., Kanie, T., Susaki, E., Onoyama, I., Tateishi, Y., Nakayama, K., and Nakayama, K.I. (2011). p57 is required for quiescence and maintenance of adult hematopoietic stem cells. Cell Stem Cell 9, 262-271.

Mazo, I.B., Massberg, S., and von Andrian, U.H. (2011). Hematopoietic stem and progenitor cell trafficking. Trends Immunol 32, 493-503.

McGlincy, N.J., and Ingolia, N.T. (2017). Transcriptome-wide measurement of translation by ribosome profiling. Methods 126, 112129.

Milyavsky, M., Gan, O.I., Trottier, M., Komosa, M., Tabach, O., Notta, F., Lechman, E., Hermans, K.G., Eppert, K., Konovalova, Z., et al. (2010). A distinctive DNA damage response in human hematopoietic stem cells reveals an apoptosis-independent role for p53 in self-renewal. Cell Stem Cell 7, 186-197.

Mohammad, K., Dakik, P., Medkour, Y., Mitrofanova, D., and Titorenko, V. 
I. (2019). Quiescence entry, maintenance, and exit in adult stem cells. Int J Mol Sci 20, 2158.

Mohrin, M., Bourke, E., Alexander, D., Warr, M.R., Barry-Holson, K., Le Beau, M.M., Morrison, C.G., and Passegué, E. (2010). Hematopoietic stem cell quiescence promotes error-prone DNA repair and mutagenesis. Cell Stem Cell 7, 174-185.

Morrison, S.J., and Kimble, J. (2006). Asymmetric and symmetric stemcell divisions in development and cancer. Nature 441, 1068-1074.

Morrison, J.A., Box, A.C., McKinney, M.C., McLennan, R., and Kulesa, P. M. (2015). Quantitative single cell gene expression profiling in the avian embryo. Dev Dyn 244, 774-784.

Mortensen, M., Soilleux, E.J., Djordjevic, G., Tripp, R., Lutteropp, M., Sadighi-Akha, E., Stranks, A.J., Glanville, J., Knight, S., W. Jacobsen, S.E., et al. (2011). The autophagy protein Atg7 is essential for hematopoietic stem cell maintenance. J Exp Med 208, 455-467.

Ni, F., Yu, W.M., Wang, X., Fay, M.E., Young, K.M., Qiu, Y., Lam, W.A., Sulchek, T.A., Cheng, T., Scadden, D.T., et al. (2019). Ptpn21 controls hematopoietic stem cell homeostasis and biomechanics. Cell Stem Cell 24, 608-620.e6.

Nitta, E., Yamashita, M., Hosokawa, K., Xian, M.J., Takubo, K., Arai, F., Nakada, S., and Suda, T. (2011). Telomerase reverse transcriptase protects ATM-deficient hematopoietic stem cells from ROS-induced apoptosis through a telomere-independent mechanism. Blood 117, 4169-4180.

North, T.E., Goessling, W., Walkley, C.R., Lengerke, C., Kopani, K.R., Lord, A.M., Weber, G.J., Bowman, T.V., Jang, I.H., Grosser, T., et al. (2007). Prostaglandin E2 regulates vertebrate haematopoietic stem cell homeostasis. Nature 447, 1007-1011.

Papayannopoulou, T., Craddock, C., Nakamoto, B., Priestley, G.V., and Wolf, N.S. (1995). The VLA4/VCAM-1 adhesion pathway defines contrasting mechanisms of lodgement of transplanted murine hemopoietic progenitors between bone marrow and spleen. Proc Natl Acad Sci USA 92, 9647-9651.

Papayannopoulou, T., and Scadden, D.T. (2008). Stem-cell ecology and stem cells in motion. Blood 111, 3923-3930.

Pei, W., Feyerabend, T.B., Rössler, J., Wang, X., Postrach, D., Busch, K., Rode, I., Klapproth, K., Dietlein, N., Quedenau, C., et al. (2017). Polylox barcoding reveals haematopoietic stem cell fates realized in vivo. Nature 548, 456-460.

Pei, W., Shang, F., Wang, X., Fanti, A.K., Greco, A., Busch, K., Klapproth, K., Zhang, Q., Quedenau, C., Sauer, S., et al. (2020). Resolving fates and single-cell transcriptomes of hematopoietic stem cell clones by polyloxexpress barcoding. Cell Stem Cell 27, 383-395.e8.

Pierce, H., Zhang, D., Magnon, C., Lucas, D., Christin, J.R., Huggins, M., Schwartz, G.J., and Frenette, P.S. (2017). Cholinergic signals from the CNS regulate G-CSF-mediated HSC mobilization from bone marrow via a glucocorticoid signaling relay. Cell Stem Cell 20, 648-658.e4.

Pinho, S., and Frenette, P.S. (2019). Haematopoietic stem cell activity and interactions with the niche. Nat Rev Mol Cell Biol 20, 303-320.

Potten, C.S. (2001). Apoptosis in oral mucosa: lessons from the crypt. A commentary. Oral Dis 7, 81-85.

Qian, H., Tryggvason, K., Jacobsen, S.E., and Ekblom, M. (2006). Contribution of $\alpha 6$ integrins to hematopoietic stem and progenitor cell homing to bone marrow and collaboration with $\alpha 4$ integrins. Blood 107, 3503-3510.

Qian, P., De Kumar, B., He, X.C., Nolte, C., Gogol, M., Ahn, Y., Chen, S., Li, Z., Xu, H., Perry, J.M., et al. (2018). Retinoid-sensitive epigenetic regulation of the Hoxb cluster maintains normal hematopoiesis and inhibits leukemogenesis. Cell Stem Cell 22, 740-754.e7.

Reya, T., Duncan, A.W., Ailles, L., Domen, J., Scherer, D.C., Willert, K., Hintz, L., Nusse, R., and Weissman, I.L. (2003). A role for Wnt signalling in self-renewal of haematopoietic stem cells. Nature 423, 409-414.

Sagot, I., and Laporte, D. (2019). Quiescence, an individual journey. Curr Genet 65, 695-699.

Samavarchi-Tehrani, P., Samson, R., and Gingras, A.C. (2020). Proximity dependent biotinylation: key enzymes and adaptation to proteomics approaches. Mol Cell Proteomics 19, 757-773.

Sawai, C.M., Babovic, S., Upadhaya, S., Knapp, D.J.H.F., Lavin, Y., Lau, C.M., Goloborodko, A., Feng, J., Fujisaki, J., Ding, L., et al. (2016). Hematopoietic stem cells are the major source of multilineage hematopoiesis in adult animals. Immunity 45, 597-609.

Signer, R.A.J., Magee, J.A., Salic, A., and Morrison, S.J. (2014). Haematopoietic stem cells require a highly regulated protein synthesis rate. Nature 509, 49-54.

Simsek, T., Kocabas, F., Zheng, J., Deberardinis, R.J., Mahmoud, A.I., Olson, E.N., Schneider, J.W., Zhang, C.C., and Sadek, H.A. (2010). The distinct metabolic profile of hematopoietic stem cells reflects their location in a hypoxic niche. Cell Stem Cell 7, 380-390.

Sugimura, R., He, X.C., Venkatraman, A., Arai, F., Box, A., Semerad, C., Haug, J.S., Peng, L., Zhong, X.B., Suda, T., et al. (2012). Noncanonical Wnt signaling maintains hematopoietic stem cells in the niche. Cell 150, 351-365.

Sugiyama, T., Omatsu, Y., and Nagasawa, T. (2019). Niches for hematopoietic stem cells and immune cell progenitors. Int Immunol $31,5-11$.

Sun, J., Ramos, A., Chapman, B., Johnnidis, J.B., Le, L., Ho, Y.J., Klein, A., Hofmann, O., and Camargo, F.D. (2014). Clonal dynamics of native haematopoiesis. Nature 514, 322-327.

Szade, K., Gulati, G.S., Chan, C.K.F., Kao, K.S., Miyanishi, M., Marjon, K. D., Sinha, R., George, B.M., Chen, J.Y., and Weissman, I.L. (2018). Where hematopoietic stem cells live: the bone marrow niche. Antioxid Redox Signal 29, 191-204.

Takayama, N., Murison, A., Takayanagi, S.I., Arlidge, C., Zhou, S., GarciaPrat, L., Chan-Seng-Yue, M., Zandi, S., Gan, O.I., Boutzen, H., et al. (2021). The transition from quiescent to activated states in human hematopoietic stem cells is governed by dynamic 3D genome reorganization. Cell Stem Cell 28, 488-501.e10.

Tokoyoda, K., Egawa, T., Sugiyama, T., Choi, B.I., and Nagasawa, T. (2004). Cellular niches controlling B lymphocyte behavior within bone marrow during development. Immunity 20, 707-718.

Upadhaya, S., Sawai, C.M., Papalexi, E., Rashidfarrokhi, A., Jang, G., Chattopadhyay, P., Satija, R., and Reizis, B. (2018). Kinetics of adult hematopoietic stem cell differentiation in vivo. J Exp Med 215, 28152832.

van Velthoven, C.T.J., de Morree, A., Egner, I.M., Brett, J.O., and Rando, T.A. (2017). Transcriptional profiling of quiescent muscle stem cells in vivo. Cell Rep 21, 1994-2004.

van Velthoven, C.T.J., and Rando, T.A. (2019). Stem cell quiescence: dynamism, restraint, and cellular idling. Cell Stem Cell 24, 213-225.

Viatour, P., Somervaille, T.C., Venkatasubrahmanyam, S., Kogan, S., McLaughlin, M.E., Weissman, I.L., Butte, A.J., Passegué, E., and Sage, J. (2008). Hematopoietic stem cell quiescence is maintained by compound contributions of the retinoblastoma gene family. Cell Stem Cell 3, 416-428.

Wang, W., Yu, S., Zimmerman, G., Wang, Y., Myers, J., Yu, V.W.C., Huang, D., Huang, X., Shim, J., Huang, Y., et al. (2015). Notch receptor-ligand engagement maintains hematopoietic stem cell quiescence and niche retention. Stem Cells 33, 2280-2293.

Wang, Y.V., Leblanc, M., Fox, N., Mao, J.H., Tinkum, K.L., Krummel, K., Engle, D., Piwnica-Worms, D., Piwnica-Worms, H., Balmain, A., et al. (2011). Fine-tuning p53 activity through C-terminal modification significantly contributes to HSC homeostasis and mouse radiosensitivity. Genes Dev 25, 1426-1438.

Wei, P., Dove, K.K., Bensard, C., Schell, J.C., and Rutter, J. (2018). The force is strong with this one: metabolism (over)powers stem cell fate. Trends Cell Biol 28, 551-559.

Wilkinson, A.C., Ishida, R., Kikuchi, M., Sudo, K., Morita, M., Crisostomo, R.V., Yamamoto, R., Loh, K.M., Nakamura, Y., Watanabe, M., et al. (2019). Long-term ex vivo haematopoietic-stemcell expansion allows nonconditioned transplantation. Nature 571, 117121.

Wilson, A., Laurenti, E., Oser, G., van der Wath, R.C., Blanco-Bose, W., Jaworski, M., Offner, S., Dunant, C.F., Eshkind, L., Bockamp, E., et al. 
(2008). Hematopoietic stem cells reversibly switch from dormancy to self-renewal during homeostasis and repair. Cell 135, 1118-1129.

Winkler, I.G., Sims, N.A., Pettit, A.R., Barbier, V., Nowlan, B., Helwani, F., Poulton, I.J., van Rooijen, N., Alexander, K.A., Raggatt, L.J., et al. (2010). Bone marrow macrophages maintain hematopoietic stem cell (HSC) niches and their depletion mobilizes HSCs. Blood 116, 48154828.

Wojtowicz, E.E., Lechman, E.R., Hermans, K.G., Schoof, E.M., Wienholds, E., Isserlin, R., van Veelen, P.A., Broekhuis, M.J.C., Janssen, G.M.C., Trotman-Grant, A., et al. (2016). Ectopic miR-125a expression induces long-term repopulating stem cell capacity in mouse and human hematopoietic progenitors. Cell Stem Cell 19, 383-396.

Xie, X., Cheng, X., Wang, G., Zhang, B., Liu, M., Chen, L., Cheng, H., Hao, S., Zhou, J., Zhu, P., et al. (2021). Single-cell transcriptomes of peripheral blood cells indicate and elucidate severity of COVID-19. Sci China Life Sci doi: 10.1007/s11427-020-1880-y.

Yamashita, M., Nitta, E., and Suda, T. (2015). Aspp1 preserves hematopoietic stem cell pool integrity and prevents malignant transformation. Cell Stem Cell 17, 23-34.

Yamashita, M., Nitta, E., and Suda, T. (2016). Regulation of hematopoietic stem cell integrity through p53 and its related factors. Ann NY Acad Sci 1370, 45-54.

Yu, H., Shen, H., Yuan, Y., XuFeng, R., Hu, X., Garrison, S.P., Zhang, L., Yu, J., Zambetti, G.P., and Cheng, T. (2010). Deletion of Puma protects hematopoietic stem cells and confers long-term survival in response to high-dose $\gamma$-irradiation. Blood 115, 3472-3480.

Yuan, L., Sakamoto, N., Song, G., and Sato, M. (2013). Low-level shear stress induces human mesenchymal stem cell migration through the SDF-1/CXCR4 axis via MAPK signaling pathways. Stem Cells Dev 22, 2384-2393.

Zhang, J., Supakorndej, T., Krambs, J.R., Rao, M., Abou-Ezzi, G., Ye, R.Y., Li, S., Trinkaus, K., and Link, D.C. (2019). Bone marrow dendritic cells regulate hematopoietic stem/progenitor cell trafficking. J Clin Invest 129, 2920-2931.

Zhang, Z., Zhu, P., Zhou, Y., Sheng, Y., Hong, Y., Xiang, D., Qian, Z., Mosenson, J., and Wu, W.S. (2017). A novel slug-containing negativefeedback loop regulates SCF/c-Kit-mediated hematopoietic stem cell self-renewal. Leukemia 31, 403-413.

Zhao, M., Ross, J.T., Itkin, T., Perry, J.M., Venkatraman, A., Haug, J.S., Hembree, M.J., Deng, C.X., Lapidot, T., He, X.C., et al. (2012). FGF signaling facilitates postinjury recovery of mouse hematopoietic system. Blood 120, 1831-1842.

Zhao, Y., Zhou, J., Liu, D., Dong, F., Cheng, H., Wang, W., Pang, Y., Wang, Y., Mu, X., Ni, Y., et al. (2015). ATF4 plays a pivotal role in the development of functional hematopoietic stem cells in mouse fetal liver. Blood 126, 2383-2391.

Zhou, B.O., Yu, H., Yue, R., Zhao, Z., Rios, J.J., Naveiras, O., and Morrison, S.J. (2017). Bone marrow adipocytes promote the regeneration of stem cells and haematopoiesis by secreting SCF. Nat Cell Biol 19, 891-903.

Zhou, J., Xu, J., Zhang, L., Liu, S., Ma, Y., Wen, X., Hao, J., Li, Z., Ni, Y., Li, X., et al. (2019). Combined single-cell profiling of lncRNAs and functional screening reveals that $\mathrm{H} 19$ is pivotal for embryonic hematopoietic stem cell development. Cell Stem Cell 24, 285-298.e5. 